\title{
Original Article \\ Red Mold Rice Mitigates Oral Carcinogenesis in 7,12-Dimethyl-1,2-Benz[a]anthracene-Induced Oral Carcinogenesis in Hamster
}

\author{
Ruei-Lan Tsai, ${ }^{1}$ Bing-Ying Ho, ${ }^{2}$ and Tzu-Ming Pan ${ }^{2}$ \\ ${ }^{1}$ R\&D Division, Sunway Biotechnology Company Limited, Taipei, Taiwan \\ ${ }^{2}$ Institute of Microbiology and Biochemistry, College of Life Science, National Taiwan University, Taipei, Taiwan
}

Correspondence should be addressed to Tzu-Ming Pan, tmpan@ntu.edu.tw

Received 29 July 2009; Accepted 24 November 2009

Copyright ( 2011 Ruei-Lan Tsai et al. This is an open access article distributed under the Creative Commons Attribution License, which permits unrestricted use, distribution, and reproduction in any medium, provided the original work is properly cited.

\begin{abstract}
The prevalence of oral tumor has exponentially increased in recent years; however, the effective therapies or prevention strategies are not sufficient. Red mold rice is a traditional Chinese food, and several reports have demonstrated that red mold rice had an anti-tumor effect. However, the possible anti-tumor mechanisms of the red mold rice are unclear. In this study, we examined the anti-tumor effect of red mold rice on 7,12-dimethyl-1,2-benz[a] anthracene (DMBA)-induced oral tumor in hamster. The ethanol extract of red mold rice (RMRE) treatment significantly decreases the levels of DMBA-induced reactive oxygen species, nitro oxide and prostaglandin $\mathrm{E}_{2}$ than those of the lovastatin-treated group $(P<.001)$. Moreover, RMRE decreases the formation of oral tumor induced by DMBA. Monacolin K, monascin, ankaflavin or other red mold rice metabolites had been reported to decrease inflammation and oxidative stress and exerted anti-tumor effects. Therefore, we evaluated the anti-inflammation and anti-oxidative stress effects of monacolin K, monascin, ankaflavin and citrinin in lipopolysaccharide-treated RAW264.7 cells. We found that RMRE reduced the LPS-induced nitrite levels in RAW264.7 cells better than monacolin K, monascin, ankaflavin or citrinin $(P<.05)$.
\end{abstract}

\section{Introduction}

The incidence and mortality rates of head and neck tumor have been increasing in recent years, especially oral tumor [1]. Despite improvement in surgery, radiotherapy and chemotherapy, the 5-year survival rate of head and neck cancers have improved marginally [2]. Therefore, it is important to renew in chemoprevention as a means of reducing the incidence and mortality of these cancers.

Monascus-fermented rice, known as red mold rice, is a common food item found in China, used to enhance the color and flavor of food, as well as a traditional medicine for digestive and vascular functions $[3,4]$. Currently, red mold rice is regarded as a popular health food for hypolipidemic treatment in Asia and the United States and several components of red mold rice have been identified. Monacolins, a group of 3-hydroxzy-3-methyglutaryl-coenzyme A reductase inhibitors with characteristics identical to those of statins, are the functional ingredients of red mold rice with hypolipidemic ability $[5,6]$. In addition, several secondary metabolites have also been identified, such as azaphilone pigments (e.g., monascin, ankaflavin, rubropunctatin, monascorburin, ruborpunctamine and monascorburamine) exhibited anti-inflammatory and anti-tumor activities or a group of antioxidants, including dimerumic acid, tannin and phenol [7-12].

Oxidative stress due to high flux of oxidants has been implicated in the pathogenesis of several cancers, including oral cancer [13]. Over-production of reactive oxygen species (ROS) has been well documented in betel quid and tobacco chewers [14]. ROS-mediated oxidative damage results in deoxyribonucleic acid damage, and thereby contributes to mutagenesis and carcinogenesis [15]. 7,12-Dimethyl1,2-benz[a] anthracene (DMBA) is a potent carcinogen. It has been suggested that DMBA, on metabolic activation, induces cancer through an oxidative mediated genotoxicity by incorporating diolepoxide and other ROS into DNA [16]. The DMBA-induced buccal-pouch mucosa carcinogenesis in hamster is one of the most extensively used models for oral carcinogenesis investigation since it has many morphological 
and histological similarities with human oral carcinoma [17].

In this study, we investigated the ability of the ethanol extract of red mold rice (RMRE) in DMBA-induced hamster buccal pouch squamous-cell carcinogenesis and we also clarified the possible anti-tumor effect of RMRE.

\section{Methods}

2.1. Chemical and Reagents. Lovastatin was obtained from Standard Chem. \& Pharm. Co. Ltd (Tainan, Taiwan) and celecoxib was purchased from Pfizer (NY, USA). 7,12Dimethyl-1,2-benz[a] anthracene (DMBA), sodium nitrite, lipopolysaccharide (LPS) and nitro blue tetrazolium (NBT) were purchased from Sigma-Aldrich. (St. Louis, MO, USA). Prostaglandin $\mathrm{E}_{2}$ immunoassay kit was purchased from Cayman Chemical Co. (Ann Arbor, MI, USA). The NO assay kit was purchased from R\&D (Minneapolis, MN, USA).

\subsection{Preparation of Ethanol Extraction of Red Mold Rice. The} long-grain rice was purchased from a local supermarket in Taiwan to be used for red mold rice production under solidstate cultivation. Monascus purpureus NTU 301 was used to prepare red mold rice via the method in previous study [6]. After fermentation, the crushed and dried red mold rice ( $1 \mathrm{~kg}$ ) was further extracted by ethanol at $50^{\circ} \mathrm{C}$ for 3 days. The extracts were concentrated by vaccum filtration device and dried by lyophilization. The key components in ethanol extraction of red mold rice (RMRE) contain $5.092 \mathrm{mg}$ monacolin $\mathrm{K}$ per g powder, $0.028 \mathrm{mg}$ citrinin per g powder, $12.844 \mathrm{mg}$ per g monascin and $4.124 \mathrm{mg}$ ankaflavin per $\mathrm{g}$ powder. The methods for analyzing the key components in RMRE are cited from these papers $[18,19]$. The dried ethanol extract of $M$. purpureus NTU 301-fermented red mold rice was resolved with ethanol at a final concentration of $50 \mathrm{mg} \mathrm{mL}^{-1}$ and stored at $4^{\circ} \mathrm{C}$.

2.3. DMBA-Induced Oral Tumor Model. Five-week-old male Syrian golden hamsters were purchased from National Laboratory Animal Center (Taipei, Taiwan). Hamsters were housed in a temperature at $23 \pm 2{ }^{\circ} \mathrm{C}, 50 \pm 10 \%$ humidity and kept on a 12:12 light: dark cycle. The animal procedures were performed according to the Guide for the Care and Use of Laboratory Animals of the National Institutes of Health, as well as the guidelines of the Animal Welfare Act. The model of DMBA-induced hamster cheek pouch carcinogenesis was modified from Salley [20]. As shown Figure 1, the animals were treated by painting a buccal pouch three times a day for 6 weeks with a $0.5 \%$ solution of DMBA dissolved in mineral oil. The dosage of RMRE was calculated in accordance with Boyd's formula of body surface area as recommended by the Food and Drug Administration (FDA) [6]. A dose of $22.7 \mathrm{mg}$ RMRE per kg body weight was fed in hamster that is recommended to the supplement of the daily diet at $200 \mathrm{mg}$ for an adult with a weight of $65 \mathrm{~kg}$ and a height of $170 \mathrm{~cm}$. And lovastatin group provided $0.15 \mathrm{mg}$ lovastatin per kg body weight that is equal to monacolin K in RMRE group. Each animal of positive control group was treated with $100 \mu \mathrm{L} 6 \%$ celecoxib following the method described in previous study $[21,22]$. Animals were killed after 14 weeks and the tumor volume and burden were determined as follows [23].

Tumor volume was measured using the formula $V=4 / 3$ $\left(D_{1} / 2\right)\left(D_{2} / 2\right)\left(D_{3} / 2\right)$, where $D_{1}, D_{2}$ and $D_{3}$ are the three diameter $(\mathrm{mm})$ of the tumor:

Tumor burden

$$
=\text { Total numbers of tumors } \times \text { Mean volume }\left(4 / 3 \pi \mathrm{r}^{3}\right) \text {. }
$$

Results are presented as mean $\pm \mathrm{SD}$.

2.4. Determination of $\mathrm{ROS}, \mathrm{NO}_{2}{ }^{-} / \mathrm{NO}_{3}{ }^{-}$and PGE Levels in Tissue Homogenate. In the measurement of ROS, $100 \mu \mathrm{L}$ homogenates of tissue were added to 96 -well plates, and reacted with $25 \mu \mathrm{L} \mathrm{NBT}\left(10 \mathrm{mg} \mathrm{mL}^{-1}\right)$ at $37^{\circ} \mathrm{C}$ for $2 \mathrm{~h}$ and measured by absorbance at $600 \mathrm{~nm}$ [24]. In the measurement of $\mathrm{NO}_{2}{ }^{-} / \mathrm{NO}_{3}{ }^{-}$or $\mathrm{PGE}_{2}, 100 \mu \mathrm{L}$ homogenates were filtered by $10 \mathrm{kD}$ filter, and then measured by the $\mathrm{NO}$ kit or a prostaglandin $\mathrm{E}_{2}$ immunoassay kit [25].

2.5. Cell Culture. Murine macrophage cell line, RAW264.7, was obtained from the Bioresource Collection and Research Center (BCRC) in Taiwan and maintained in Dulbecco's modified Eagle's medium supplemented with $10 \%$ fetal bovine serum at $37^{\circ} \mathrm{C}$ in a humidified atmosphere of $5 \%$ $\mathrm{CO}_{2}$. Cells in 24 -well plates $\left(2 \times 10^{5}\right.$ cells per well $)$ were treated with LPS (100 $\mathrm{ng} \mathrm{mL}^{-1}$ ) and test compounds (RMRE, lovastatin, citrinin, monascin and ankaflavin).

2.6. Nitrite and $P G E_{2}$ Production Determination. Nitrite levels in cell culture supernatants were determined by Griess reaction. The supernatants $(0.05 \mathrm{~mL})$ were simultaneously treated with $0.05 \mathrm{~mL}$ Griess reagent A (1\% sulfanilamide in $\left.2.5 \% \mathrm{H}_{3} \mathrm{PO}_{4}\right)$ and $0.05 \mathrm{~mL}$ Griess reagent $\mathrm{B}(0.1 \% \mathrm{~N}-1$ naphthyl ethylene diaminedihydrochloride in $2.5 \% \mathrm{H}_{3} \mathrm{PO}_{4}$ ) for $10 \mathrm{~min}$ at room temperature. $\mathrm{NaNO}_{2}$ was used to generate a standard curve; nitrite production was measured by a spectrophotometer at $570 \mathrm{~nm}$ [26]. $\mathrm{PGE}_{2}$ concentrations were determined by a prostaglandin $\mathrm{E}_{2}$ immunoassay kit [25].

2.7. Western Blot Analysis. RAW264.7 cells $\left(2 \mathrm{~mL}, 4 \times 10^{6}\right.$ cells $\mathrm{mL}^{-1}$ ), grown in a $6-\mathrm{cm}$ dish, were incubated with or without LPS in the absence or presence of the test compounds for $24 \mathrm{~h}$, respectively. Cells were lysed with icecold PBS containing 1\% nonidet P-40, $1 \mathrm{mM}$ of phenylmethylsulfonyl fluoride, $10 \mathrm{mg} \mathrm{mL}^{-1}$ of aprotinin, $50 \mathrm{mM}$ of sodium fluoride and $2 \mathrm{mM}$ of sodium orthovanadate (Sigma-Aldrich). Protein lysates $(30 \mu \mathrm{g})$ were separated using $10 \%$ SDS-polyacrylamide gel electrophoresis and transferred to a polyvinylidene difluoride membrane (Millipore, Billerica, MA, USA). After they had been blocked with $10 \%$ milk in TBS-T (10 mM Tris ( $\mathrm{pH} 7.6), 150 \mathrm{mM} \mathrm{NaCl}$ and $0.05 \%$ Tween 20), the membranes were incubated with appropriate antibodies containing primary antibody and anti-rabbit or 


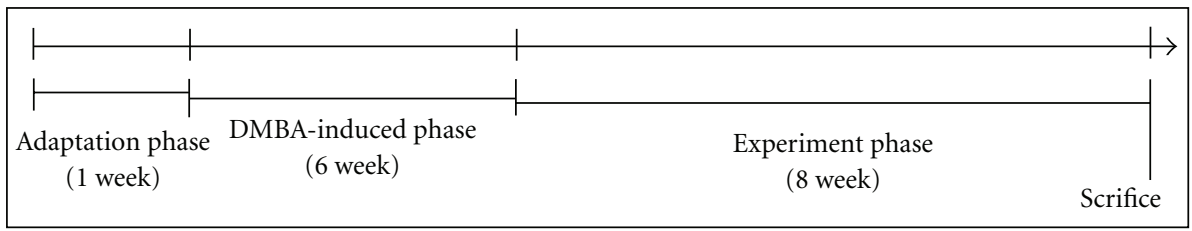

FIGURE 1: The flowchart of oral tumor induction and drug treatment. To induce oral tumor formation (DMBA-induced phase), $0.5 \%$ DMBA solution was prepared in mineral oil and applied to the entire mucosal surface of the right buccal pouch for 3 times/week. After 6 weeks, $6 \%$ celecoxib, RMRE $\left(22.7 \mathrm{mg} \mathrm{kg}^{-1}\right)$ or lovastatin $\left(0.15 \mathrm{mg} \mathrm{kg}^{-1}\right)$ was administrated with mineral oil to DMBA-induced oral tumor hamsters (experiment phase).

TABLE 1: Incidence of oral neoplasm in control and experiment animal groups $(n=5)$.

\begin{tabular}{lllll}
\hline Group & Treatment & No. of tumor & Mean tumor volume $\left(\mathrm{mm}^{3}\right)$ & Tumor burden $\left(\mathrm{mm}^{3}\right)$ \\
\hline D & DMBA 6 weeks alone & 18 & $26.92 \pm 20.11$ & $92.86 \pm 63.68$ \\
A & DMBA 6 weeks + 6\% celecoxib & 9 & $48.57 \pm 20.86$ & $72.85 \pm 28.59$ \\
B & DMBA 6 weeks + RMRE & 10 & $23.74 \pm 21.34$ & $35.76 \pm 18.49^{*}$ \\
C & DMBA 6 weeks + Lovastatin & 10 & $42.25 \pm 25.42$ & $99.42 \pm 98.71$ \\
OL & Oil 14 weeks & 0 & - & - \\
\hline
\end{tabular}

${ }^{*}$ Significantly different when compared with group D $(P<.05)$ by Student's $t$-test.

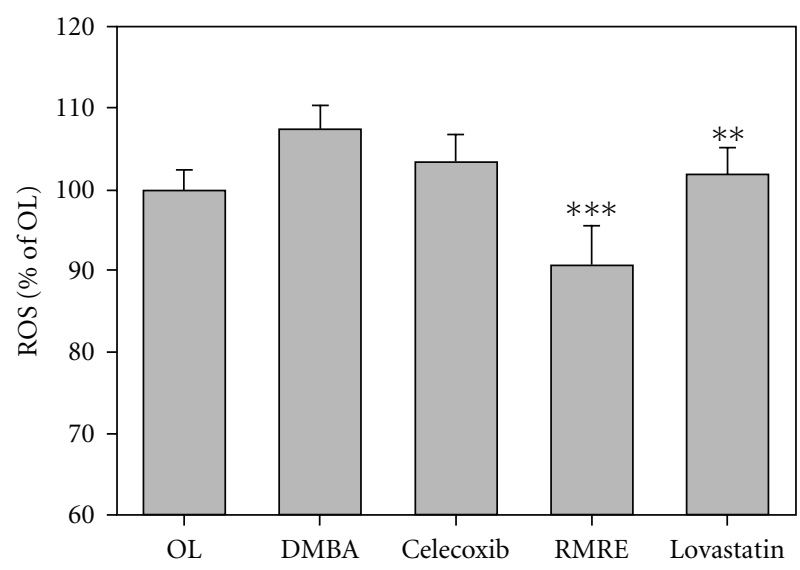

(a)

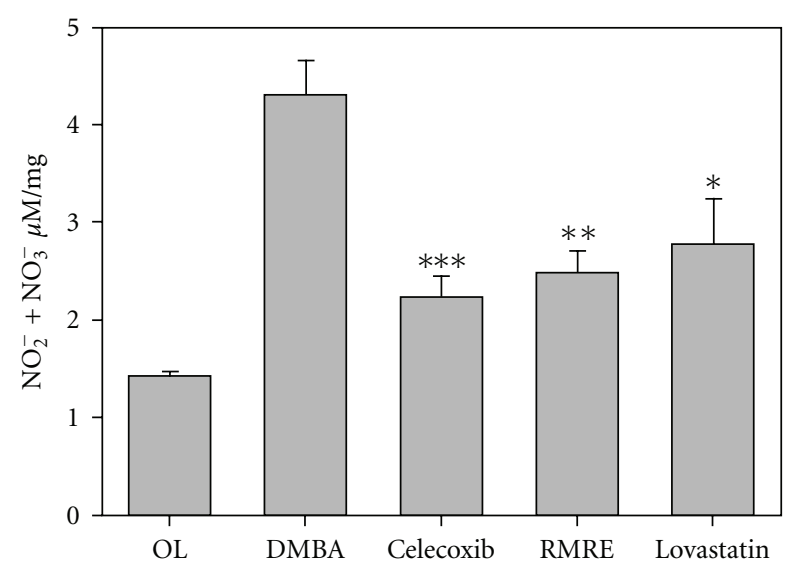

(b)

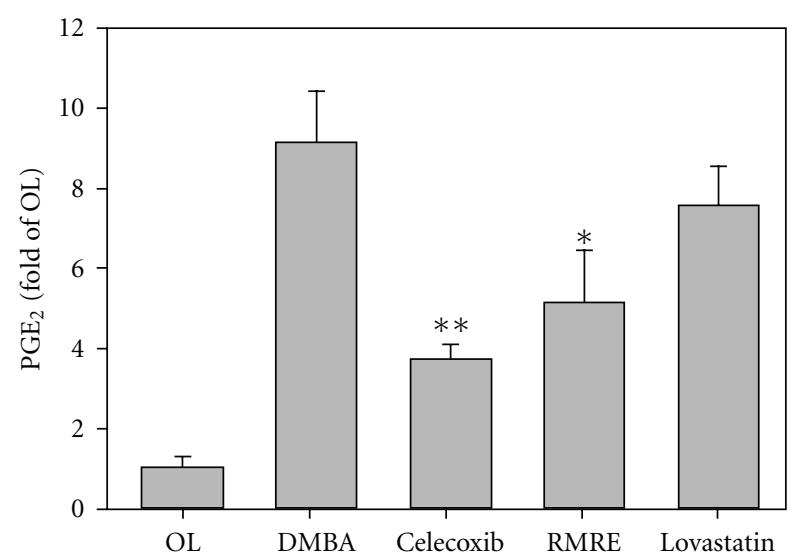

(c)

FIgURE 2: RMRE decreased ROS, $\mathrm{NO}_{2}^{-} \mathrm{NO}_{3}^{-}$and $\mathrm{PGE}_{2}$ levels in experimental hamsters. The homogenates of buccal pouch was measured levels of ROS (a), $\mathrm{NO}_{2}{ }^{-} / \mathrm{NO}_{3}{ }^{-}$(b) and $\mathrm{PGE}_{2}$ (c). Results are expressed as the mean $\pm \mathrm{SD}, n=5 . * P<.05, * * P<.01, * * * P<.001$ versus the DMBA treatment group. 


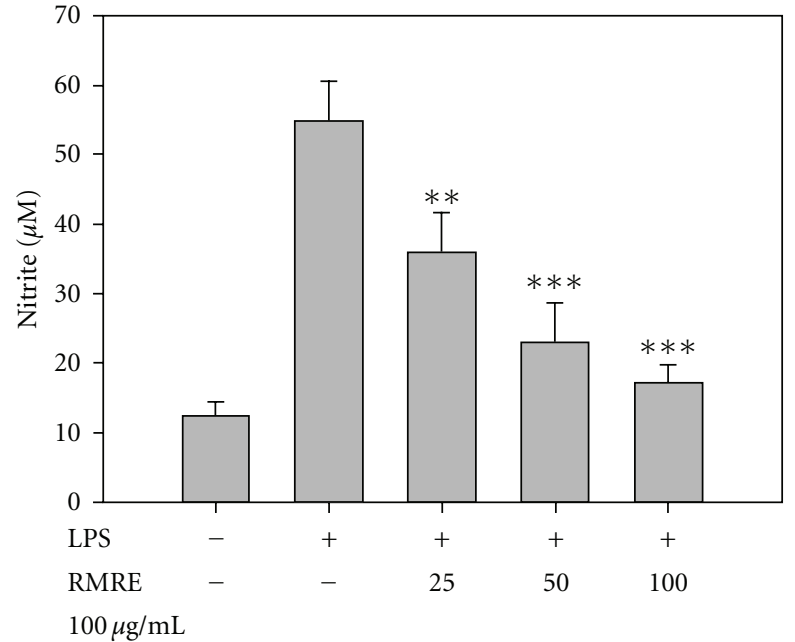

(a)

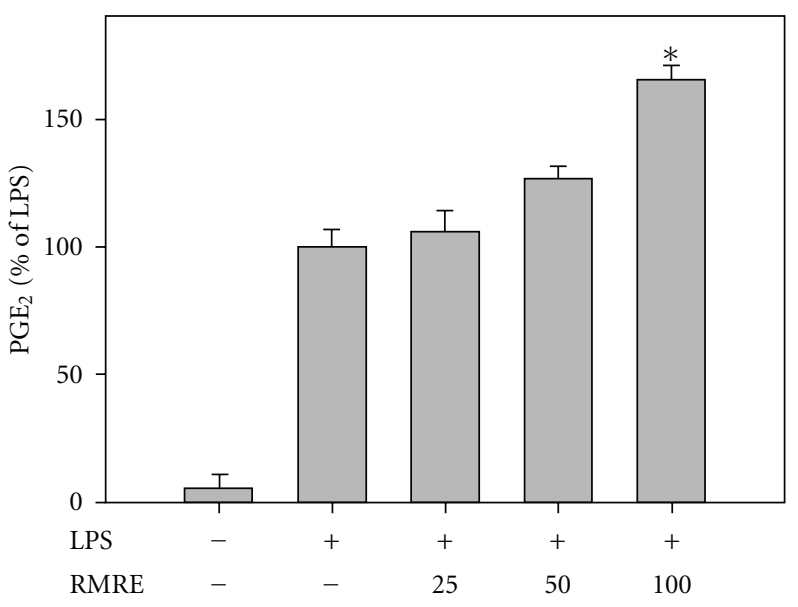

(b)

FIGURE 3: The effects of RMRE on LPS-induced nitrite and $\mathrm{PGE}_{2}$ generation in RAW264.7 cells. Various concentrations of RMRE affected the LPS-induced levels of nitrite (a) and $\mathrm{PGE}_{2}$ (b), determined at $48 \mathrm{~h}$. Results are expressed as the mean $\pm \mathrm{SD}$ for at least three independent experiments. ${ }^{* *} P<.01,{ }^{* * *} P<.001$ versus the LPS treatment group.

anti-mouse secondary horseradish peroxidase antibodies (Sigma-Aldrich), iNOS and $\beta$-actin antibody (Santa Cruz Biotechnology, Santa Cruz, CA, USA) and COX-2 antibody (Transduction Laboratories Biotechnology, Lake Placid, NY, USA). Subsequently, the blots were visualized using a chemiluminescence kit (PerkinElmer, Boston, MA, USA). $\beta$ actin was set as an internal control. The optical densities of the bands were determined using UVP autochemi image system (UVP Inc., Upland, CA, USA).

2.8. Data Analysis. Results are presented as mean \pm SD and statistical significance was determined by Student's $t$-test. $P<.05$ was considered as indicating statistical significance.

\section{Results}

3.1. RMRE Reduces Carcinogenesis in DMBA-Induced Oral Tumor Model. As shown in Table 1, DMBA treatment in hamster cheek pouch induced tumor formation, whereas mineral oil treatment as a control group did not induce the formation of oral tumor. Treatment with $6 \%$ celecoxib grossly reduced the burden of tumor. The RMRE group significantly decreased tumor burden $(P<.05)$. On the other hand, RMRE treatment exerted a better anti-tumor activity than that of lovastatin treatment alone.

3.2. RMRE Decreased ROS, and $P G E_{2}$ Levels in DMBAInduced Oral Tumor Model. As shown as Figure 2, the levels of ROS, $\mathrm{NO}_{2}{ }^{-} / \mathrm{NO}_{3}{ }^{-}$and $\mathrm{PGE}_{2}$ in the cheek pouch of hamsters in DMBA-induced oral mucositis were significantly increased as compared with the control group. RMRE treatment significantly reduced DMBA-induced increment in ROS, $\mathrm{NO}_{2}{ }^{-} / \mathrm{NO}_{3}{ }^{-}$and $\mathrm{PGE}_{2}$ levels than those of the lovastain-treated group. The lower levels of $\mathrm{NO}_{2}{ }^{-} / \mathrm{NO}_{3}{ }^{-}$and $\mathrm{PGE}_{2}$ were also observed in the celecoxib group.
3.3. Inhibition of LPS-Induced Nitrite Production by RMRE in RAW264.7 Cells. RMRE treatment has no effect on cell viability of RAW264.7 cells, determined by MTT assay (data not shown). As shown in Figure 3, RMRE inhibited nitrite production in a dose-dependent manner with an $\mathrm{IC}_{50}$ of $40.3 \mu \mathrm{g} \mathrm{mL}{ }^{-1}$ whereas RMRE had no effect on LPS-induced $\mathrm{PGE}_{2}$ production in RAW264.7 cells.

3.4. RMRE Inhibited LPS-Induced iNOS Protein Expression. We detected LPS-Induced iNOS and COX-2 protein expression after RMRE treatment for $24 \mathrm{~h}$ in RAW264.7 cells. As shown in Figure 4, LPS treatment elevated the expression of iNOS and COX-2, and RMRE significantly reduced the protein expression of iNOS $(P<.001)$, but had no effect on COX-2 levels.

3.5. Inhibitory Effects of Bioactive Compounds of RMRE on LPS-Induced Nitrite and PGE Generation in RAW264.7 Cells. As shown in Figure 5, we found that $30 \mu \mathrm{M}$ lovastatin treatment exerts no inhibition activity on LPS-induced nitrite and $\mathrm{PGE}_{2}$ generation because of the decrement in cell viability (data not shown). On the other hand, both monascin and ankaflavin in $30 \mu \mathrm{M}$ inhibited nitrite production and had no effect on $\mathrm{PGE}_{2}$ expression. Moreover, citrinin suppressed LPS-induced nitrite and $\mathrm{PGE}_{2}$ production in a dose-dependent manner. High concentrations of citrinin, monascin or ankaflavin, except lovastatin, may not lead to cell death.

\section{Discussion}

Nowadays, complementary and alternative medicine (CAM) is widely available throughout the world. Cancer patients are exposed to CAM ranging from health supplements to traditional forms of medicine like traditional Chinese medicine 

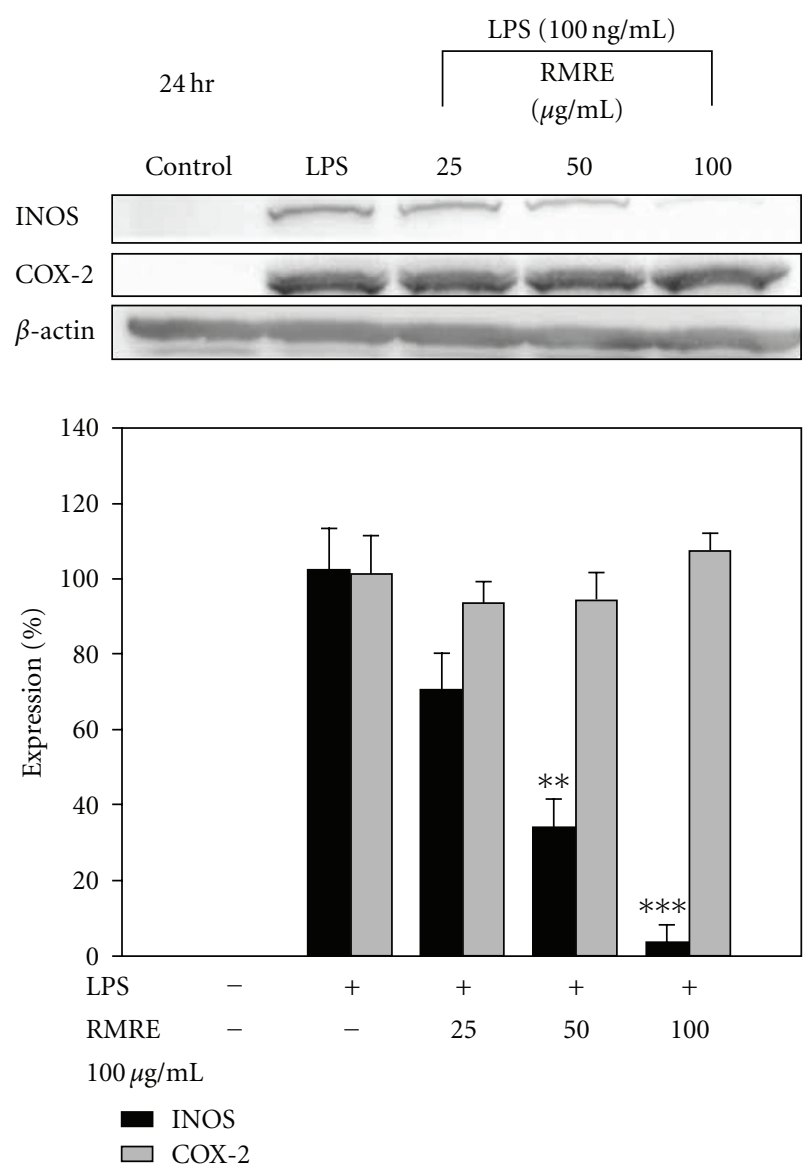

FIgURE 4: The effects of RMRE on iNOS/COX-2 expression in RAW264.7 cells. Equal amounts of total proteins ( $80 \mu \mathrm{g}$ per lane) were subjected to $10 \%$ SDS-PAGE and expression of iNOS, COX2 and $\beta$-actin was detected by western blotting analysis. $\beta$-actin was used as an internal control. Results are expressed as the mean \pm SD for at least three independent experiments. Treatment of RMRE for $24 \mathrm{~h}$ decreased LPS-induced iNOS expression. ${ }^{* *} P<.01$, $* * * P<.001$ versus the LPS treatment group.

(TCM) and traditional Indian medicine. In the past studies, the aqueous extract of neem which grows throughout India has been found to possess anti-inflammatory and potent chemopreventive activity [27].

Several studies have been demonstrated that red mold rice has an anti-tumor effect; however, the possible mechanisms and the main components of the red mold rice to exert the effect are still unclear. In this study, we found that RMRE reduces ROS, $\mathrm{NO}_{2}{ }^{-} / \mathrm{NO}_{3}{ }^{-}$and $\mathrm{PGE}_{2}$ levels in DMBA-induced oral tumor model $(P<.001)$. In addition, RMRE significantly inhibited LPS-induced nitrite levels in RAW264.7 cells than monacolin $\mathrm{K}$, monascin, ankaflavin and citrinin $(P<.05)$ and this effect might play a role in the prevention of oral tumor.

Celecoxib has a chemopreventive action against DMBAinduced cheek pouch carcinogenesis [28]. In our result, RMRE and 6\% celecoxib grossly but significantly inhibited the tumor formation (Table 1). However, we found that the lovastatin and celecoxib-treated animals had lower number of tumors but the volume was grossly greater than control animals. This effect might be because of the antiinflammation action of the drugs and this effect further prevents from the cell mutation and tumor formation. However, these drugs might have less therapeutic effect. In addition, this effect may be because of the large variation of the incidence of tumor formation in DMBA-induced oral tumor model or the dosage of RMRE treatment.

Studies indicated that elevated expression of inducible nitric oxide synthase (iNOS) was observed in both human oral carcinogenesis and chemically induced oral carcinogenesis in rodents [29, 30]. Increased iNOS expression and the generation of high NO levels might lead to oral squamous cell carcinoma development [31], implying that pharmacological inhibition of iNOS and NO might be a possible strategy for oral cancer prevention. Moreover, COX2 was shown to be over-expressed in both premalignant and malignant lesions of the oral cavity with increased expression from hyperplasia to dysplasia and squamous cell carcinogenesis (SCC) [32]. Also, the $\mathrm{PGE}_{2}$ level was increased in oral SCC tissue as compared with normal tissue [33]. In this study, we found that RMRE significantly inhibited DMBA-induced ROS, $\mathrm{NO}$ and $\mathrm{PGE}_{2}$ levels in homogenates of oral tissue $(P<.001)$. These results imply that RMRE might inhibit DMBA-induced oral tumor carcinogenesis through anti-inflammatory and antioxidant effects as shown in Figure 6.

Previous studies indicated that monacolin $\mathrm{K}$ which is one of the main active components in red mold rice at $30 \mu \mathrm{M}$ suppressed LPS-induced nitrite generation; however, the expression of COX-2 was promoted to induce $\mathrm{PGE}_{2}$ generation in RAW264.7 macrophages [34-36]. This result is inconsistent with our results in animals. In our study, RMRE has no effect on cell visibility in used concentrations and the inconsistencies of the results in vivo and in vitro might partly be because of the RMRE metabolites produced in the cell and not secreted to the medium. In addition, statins directly reduced prostaglandin $\mathrm{E} 2\left(\mathrm{PGE}_{2}\right)$ release [37] and NO production [38] in vivo, whereas statins might decrease the production of NO through an anti-inflammation effect indirectly. These effects might be applied to explain the inconsistencies in in vivo and in vitro results. We further investigated the main components in red mold rice to exert the anti-tumor effect. Thus, we used HPLC to determine the composition of RMRE, and we found that it contains $1.26 \mu \mathrm{M}$ monacolin $\mathrm{K}$ in $100 \mu \mathrm{g} \mathrm{mL}^{-1} \mathrm{RMRE}$. However, it exerts a significant effect on the inhibition of nitrite production $(P<.001)$. RMRE exerted a more effective action as compared with any one of the single components. This result reveals that RMRE might contain other compounds that inhibit nitrite production or the synergic effect between the components. We further tested $1,3,10$ and $30 \mu \mathrm{M}$ of other main components of RMRE, such as monascin, ankaflavin, citrinin in LPS-induced RAW264.7 cells. It was reported that oral administration of monascin inhibited the carcinogenesis of skin cancer, initiated by peroxynitrite or ultraviolet light and after the promotion of 12-Otetradecanoyl-phorbol-13-acetate (TPA) [9]. In addition, ankaflavin showed selective cytotoxicity to cancer cell lines 


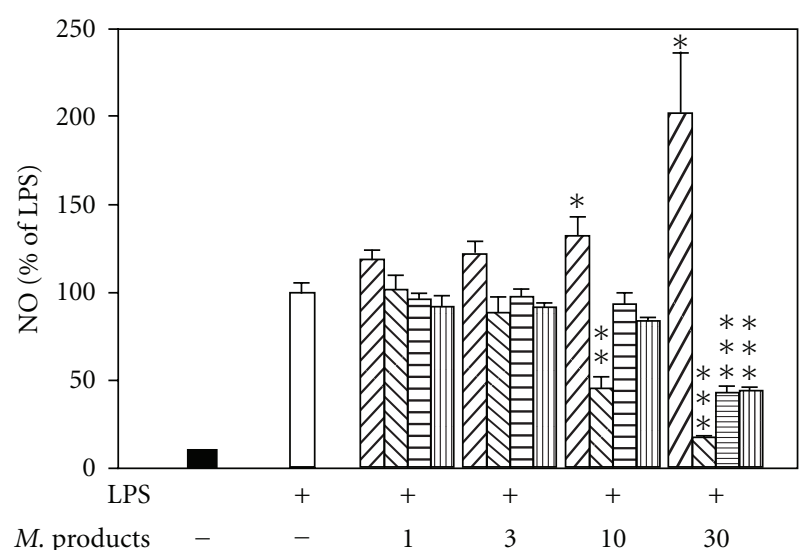

(a)

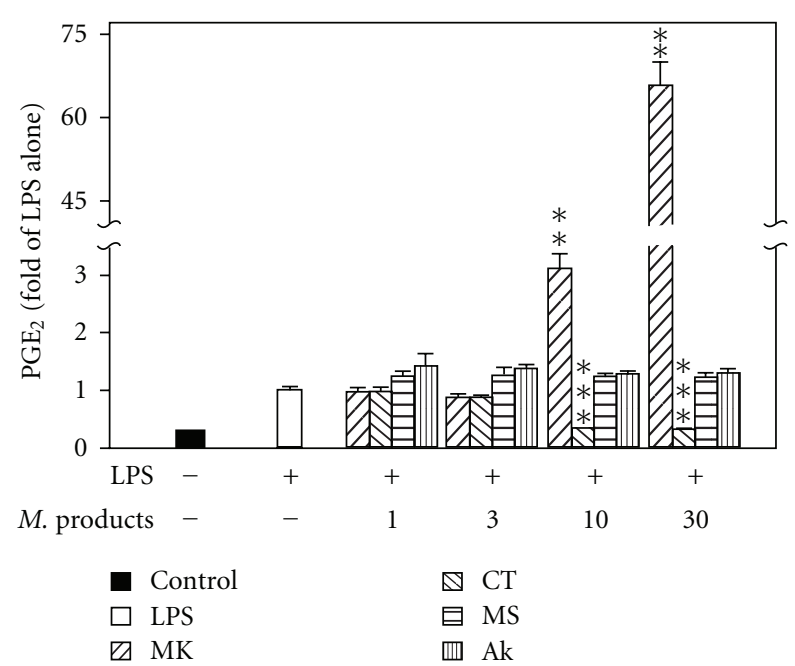

(b)

FIGURE 5: Inhibitory effects of bioactive compounds on LPS-induced nitrite and PGE $_{2}$ generation in RAW264.7 cells. Treatment of various concentrations of different compounds (lovastatin: MK, monascin: MS, ankaflavin: AK and citrinin: CT) for $48 \mathrm{~h}$ decreased LPS-induced nitrite (a) and $\mathrm{PGE}_{2}$ (b) generation. Results are expressed as the mean $\pm \mathrm{SD}$ for at least three independent experiments. ${ }^{*} P<.05,{ }^{* *} P<.01$, $* * * P<.001$ versus the LPS treatment group.

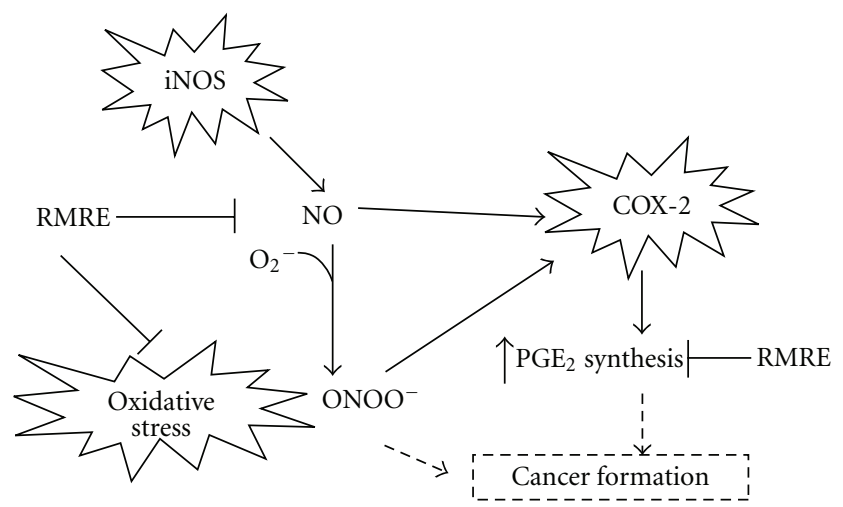

FIGURE 6: The correlations of RMRE inhibiting ROS, NO and $\mathrm{PGE}_{2}$ levels in DMBA-induced oral tumor model. iNOS expression induced NO generation and high NO levels might lead to oral squamous cell carcinoma development. On the other hand, COX-2 expression promoted $\mathrm{PGE}_{2}$ synthesis, and high $\mathrm{PGE}_{2}$ expression was increased in oral SCC tissue as compared with normal tissue. In this study, RMRE treatment had pharmacological inhibition of ROS, $\mathrm{NO}$ and $\mathrm{PGE}_{2}$ in vivo. It might be a possible strategy for oral cancer prevention.

by an apoptosis-related mechanism [39]. As shown in 4, monascin or ankaflavin at $30 \mu \mathrm{M}$ inhibits LPS-induced nitrite generation but shows no effects on $\mathrm{PGE}_{2}$ production $(P<.001)$. Ten micromolar citrinin had an inhibition activity to decrease LPS-induced nitrite $(P<.05)$ or $\mathrm{PGE}_{2}$ generation $(P<.001)$. However, $100 \mu \mathrm{g} \mathrm{mL}^{-1}$ of RMRE contains only $3.58 \mu \mathrm{M}$ monascin, $1.07 \mu \mathrm{M}$ ankaflavin and $0.01 \mu \mathrm{M}$ citrinin. The concentrations of those components are much lower than previous studies in the inhibition of nitrite generation. Thus, RMRE might inhibit LPS-induced nitrite generation through other unidentified compounds. Other studies also suggested that the matrix effects of red mold rice beyond monacolin $\mathrm{K}$ alone might be active in inhibiting cancer growth $[40,41]$. Taken together, RMRE exerts a chemoprevention activity in the inhibition of inflammation and oxidation which is possible for oral cancer prevention. In addition, our study showed that the matrix effects of RMRE beyond monacolin $\mathrm{K}$ alone may be active in mitigates oral carcinogenesis.

\section{Funding}

This study was supported by research grant (98-EC-17-A17-S2-0136) from the Technology Development Program for Academia (TDPA) of the Ministry of Economic Affairs (MOEA) of Taiwan, R.O.C.

\section{References}

[1] J. MacKenzie, K. Ah-See, N. Thakker et al., "Increasing incidence of oral cancer amongst young persons: what is the aetiology?" Oral Oncology, vol. 36, no. 4, pp. 387-389, 2000. 
[2] A. Jemal, R. C. Tiwari, T. Murray et al., "Cancer statistics, 2004," Ca-A Cancer Journal for Clinicians, vol. 54, no. 1, pp. 8-29, 2004.

[3] J. Ma, Y. Li, Q. Ye et al., "Constituents of red yeast rice, a traditional Chinese food and medicine," Journal of Agricultural and Food Chemistry, vol. 48, no. 11, pp. 5220-5225, 2000.

[4] M. Journoud and P. J. H. Jones, "Red yeast rice: a new hypolipidemic drug," Life Sciences, vol. 74, no. 22, pp. 26752683, 2004.

[5] A. Endo, "Monacolin K, a new hypocholesterolemic agent produced by a Monascus species," Journal of Antibiotics, vol. 32, no. 8, pp. 852-854, 1979.

[6] D. Heber, I. Yip, J. M. Ashley, D. A. Elashoff, R. M. Elashoff, and V. L. W. Go, "Cholesterol-lowering effects of a proprietary Chinese red-yeast-rice dietary supplement," American Journal of Clinical Nutrition, vol. 69, no. 2, pp. 231-236, 1999.

[7] Y. Aniya, I. I. Ohtani, T. Higa et al., "Dimerumic acid as an antioxidant of the mold, Monascus anka," Free Radical Biology and Medicine, vol. 28, no. 6, pp. 999-1004, 2000.

[8] Y. C. Su, J. J. Wang, T. T. Lin, and T. M. Pan, "Production of the secondary metabolites gamma-aminobutyric acid and monacolin K by Monascus," Journal of Industrial Microbiology and Biotechnology, vol. 30, pp. 41-46, 2003.

[9] T. Akihisa, H. Tokuda, M. Ukiya et al., "Anti-tumor-initiating effects of monascin, an azaphilonoid pigment from the extract of Monascus pilosus fermented rice (red-mold rice)," Chemistry and Biodiversity, vol. 2, no. 10, pp. 1305-1309, 2005.

[10] T. Akihisa, H. Tokuda, K. Yasukawa, M. Ukiya, A. Kiyota, and N. Sakamoto, "Azaphilones, furanoisophthalides, and amino acids from the extracts of Monascus pilosus fermented rice (red mold rice) and their chemopreventive effects," Journal of Agricultural and Food Chemistry, vol. 53, pp. 562-565, 2005.

[11] C.-L. Lee, J.-J. Wang, S.-L. Kuo, and T.-M. Pan, "Monascus fermentation of dioscorea for increasing the production of cholesterol-lowering agent-monacolin $\mathrm{K}$ and antiinflammation agent-monascin," Applied Microbiology and Biotechnology, vol. 72, no. 6, pp. 1254-1262, 2006.

[12] K. Yasukawa, M. Takahashi, S. Natori et al., "Azaphilones inhibit tumor promotion by 12-O-tetradecanoylphorbol-13acetate in two-stage carcinogenesis in mice," Oncology, vol. 51, no. 1, pp. 108-112, 1994.

[13] G. Ray and S. A. Husain, "Oxidants, antioxidants and carcinogenesis," Indian Journal of Experimental Biology, vol. 40, no. 11, pp. 1213-1232, 2002.

[14] U. J. Nair, J. Nair, M. D. Friesen, H. Bartsch, and H. Ohshima, "Ortho- and meta-tyrosine formation from phenylalanine in human saliva as a marker of hydroxyl radical generation during betel quid chewing," Carcinogenesis, vol. 16, no. 5, pp. 1195-1198, 1995.

[15] B. P. Yu, "Cellular defenses against damage from reactive oxygen species," Physiological Reviews, vol. 74, no. 1, pp. 139$162,1994$.

[16] A. Dipple, M. Pigott, R. C. Moschel, and N. Costantino, "Evidence that binding of 7,12-dimethylbenz(a)anthracene to DNA in mouse embryo cell cultures results in extensive substitution of both adenine and guanine residues," Cancer Research, vol. 43, pp. 4132-4135, 1983.

[17] I. B. Gimenez-Conti and T. J. Slaga, "The hamster cheek pouch carcinogenesis model," Journal of Cellular Biochemistry, vol. 52, pp. 83-90, 1993.

[18] L. Martinkova, P. Patakova-Juzlova, V. Krent et al., "Biological activities of oligoketide pigments of Monascus purpureus," Food Additives and Contaminants, vol. 16, no. 1, pp. 15-24, 1999.
[19] C.-L. Lee, J.-J. Wang, and T.-M. Pan, "Synchronous analysis method for detection of citrinin and the lactone and acid forms of monacolin $\mathrm{K}$ in red mold rice," Journal of AOAC International, vol. 89, no. 3, pp. 669-677, 2006.

[20] J. J. Salley, "Experimental carcinogenesis in the cheek pouch of the Syrian hamster," Journal of Dental Research, vol. 33, pp. 253-262, 1954.

[21] L. Feng and Z. Wang, "Chemopreventive effect of celecoxib in oral precancers and cancers," Laryngoscope, vol. 116, no. 10, pp. 1842-1845, 2006.

[22] Z. Sun, S. Sood, N. Li, D. Ramji, P. Yang, and R. A. Newman, "Involvement of the 5-lipoxygenase/leukotriene A4 hydrolase pathway in 7,12-dimethylbenz[a] anthracene (DMBA)induced oral carcinogenesis in hamster cheek pouch, and inhibition of carcinogenesis by its inhibitors," Carcinogenesis, vol. 27, pp. 1902-1908, 2006.

[23] H.-C. Cheng, H. Chien, C.-H. Liao, Y.-Y. Yang, and S.Y. Huang, "Carotenoids suppress proliferating cell nuclear antigen and cyclin D1 expression in oral carcinogenic models," Journal of Nutritional Biochemistry, vol. 18, no. 10, pp. 667675, 2007.

[24] C. L. Lee, T. F. Kuo, J. J. Wang, and T. M. Pan, "Red mold rice ameliorates impairment of memory and learning ability in intracerebroventricular amyloid beta-infused rat by repressing amyloid beta accumulation," The Journal of Neuroscience, vol. 85, pp. 3171-3182, 2007.

[25] Z. Sun, S. Sood, N. Li, D. Ramji, P. Yang, and R. A. Newman, "Involvement of the 5-lipoxygenase/leukotriene A4 hydrolase pathway in 7,12-dimethylbenz[a] anthracene (DMBA)induced oral carcinogenesis in hamster cheek pouch, and inhibition of carcinogenesis by its inhibitors," Carcinogenesis, vol. 27, pp. 1902-1908, 2006.

[26] L. C. Green, D. A. Wagner, J. Glogowski, P. L. Skipper, J. S. Wishnok, and S. R. Tannenbaum, "Analysis of nitrate, nitrite, and $\left[{ }^{15} \mathrm{~N}\right]$ nitrate in biological fluids," Analytical Biochemistry, vol. 126, pp. 131-138, 1982.

[27] S. Balasenthil, S. Arivazhagan, C. R. Ramachandran, V. Ramachandran, and S. Nagini, "Chemopreventive potential of neem (Azadirachta indica) on 7,12-dimethylbenz[a] anthracene (DMBA) induced hamster buccal pouch carcinogenesis," Journal of Ethnopharmacology, vol. 67, no. 2, pp. 189-195, 1999.

[28] L. Feng and Z. Wang, "Chemopreventive effect of celecoxib in oral precancers and cancers," Laryngoscope, vol. 116, no. 10, pp. 1842-1845, 2006.

[29] Y.-K. Chen, S.-S. Hsue, and L.-M. Lin, “The mRNA expression of inducible nitric oxide synthase in DMBA-induced hamster buccal-pouch carcinomas using reverse transcriptionpolymerase chain reaction," Journal of Oral Pathology and Medicine, vol. 31, no. 2, pp. 82-86, 2002.

[30] P. A. Brennan, M. Palacios-Callender, T. Umar et al., "Correlation between type II nitric oxide synthase and p53 expression in oral squamous cell carcinoma," British Journal of Oral and Maxillofacial Surgery, vol. 38, no. 6, pp. 627-632, 2000.

[31] S. T. Connelly, M. Macabeo-Ong, N. Dekker, R. C. K. Jordan, and B. L. Schmidt, "Increased nitric oxide levels and iNOS over-expression in oral squamous cell carcinoma," Oral Oncology, vol. 41, no. 3, pp. 261-267, 2005.

[32] B. Wen, E. Deutsch, P. Eschwege, R. De Crevoisier, E. Nasr, and F. Eschwege, "Cyclooxygenase-2 inhibitor NS398 enhances antitumor effect of irradiation on hormone refractory human prostate carcinoma cells," Journal of Urology, vol. 170, pp. 2036-2039, 2003. 
[33] R. A. Karmali, T. Wustrow, H. T. Thaler, and E. W. Strong, "Prostaglandins in carcinomas of the head and neck," Cancer Letters, vol. 22, no. 3, pp. 333-336, 1984.

[34] K.-C. Huang, C.-W. Chen, J.-C. Chen, and W.-W. Lin, "HMGCoA reductase inhibitors inhibit inducible nitric oxide synthase gene expression in macrophages," Journal of Biomedical Science, vol. 10, no. 4, pp. 396-405, 2003.

[35] J.-C. Chen, K.-C. Huang, B. Wingerd, W.-T. Wu, and W.W. Lin, "HMG-CoA reductase inhibitors induce COX-2 gene expression in murine macrophages: role of MAPK cascades and promoter elements for CREB and C/EBPbeta," Experimental Cell Research, vol. 301, no. 2, pp. 305-319, 2004.

[36] S.-C. Chun, S. Y. Jee, S. G. Lee, S. J. Park, J. R. Lee, and S. C. Kim, "Anti-inflammatory activity of the methanol extract of Moutan Cortex in LPS-activated Raw264.7 cells," EvidenceBased Complementary and Alternative Medicine, vol. 4, no. 3, pp. 327-333, 2007.

[37] G. Tringali, M. Vairano, Dello, C. Russo, P. Preziosi, and P. Navarra, "Lovastatin and mevastatin reduce basal and cytokine-stimulated production of prostaglandins from rat microglial cells in vitro: evidence for a mechanism unrelated to the inhibition of hydroxy-methyl-glutaryl CoA reductase," Neuroscience Letters, vol. 354, pp. 107-110, 2004.

[38] T.-C. Chou, Y.-F. Lin, W.-C. Wu, and K.-M. Chu, "Enhanced nitric oxide and cyclic GMP formation plays a role in the anti-platelet activity of simvastatin," British Journal of Pharmacology, vol. 153, no. 6, pp. 1281-1287, 2008.

[39] N.-W. Su, Y.-L. Lin, M.-H. Lee, and C.-Y. Ho, "Ankaflavin from Monascus-fermented red rice exhibits selective cytotoxic effect and induces cell death on Hep G2 cells," Journal of Agricultural and Food Chemistry, vol. 53, no. 6, pp. 1949-1954, 2005.

[40] M. Y. Hong, N. P. Seeram, Y. Zhang, and D. Heber, "Chinese red yeast rice versus lovastatin effects on prostate cancer cells with and without androgen receptor overexpression," Journal of Medicinal Food, vol. 11, no. 4, pp. 657-666, 2008.

[41] M. Y. Hong, N. P. Seeram, Y. Zhang, and D. Heber, "Anticancer effects of Chinese red yeast rice versus monacolin $\mathrm{K}$ alone on colon cancer cells," Journal of Nutritional Biochemistry, vol. 19, no. 7, pp. 448-458, 2008. 


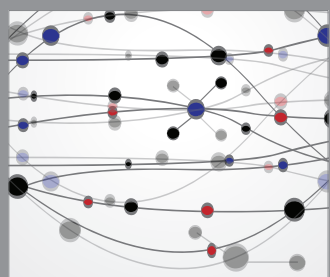

The Scientific World Journal
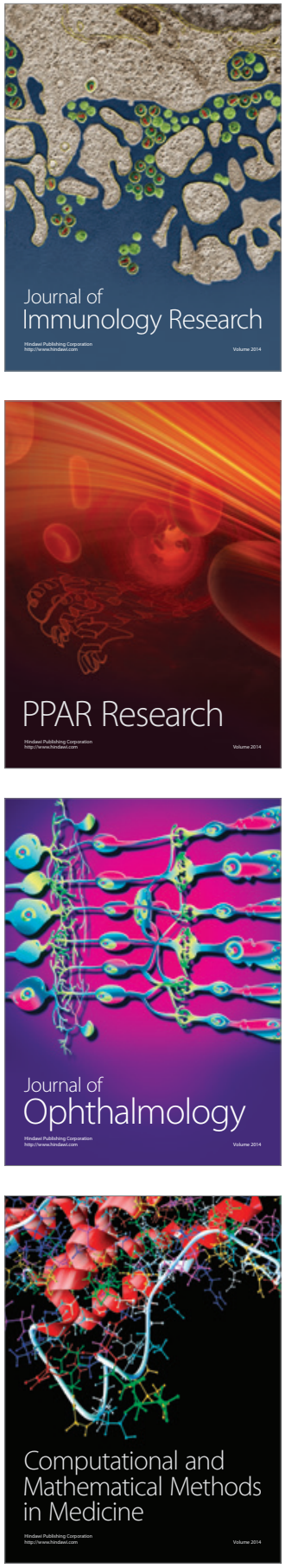

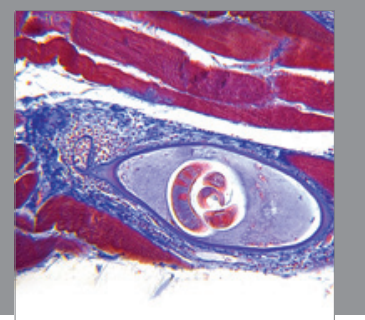

Gastroenterology

Research and Practice
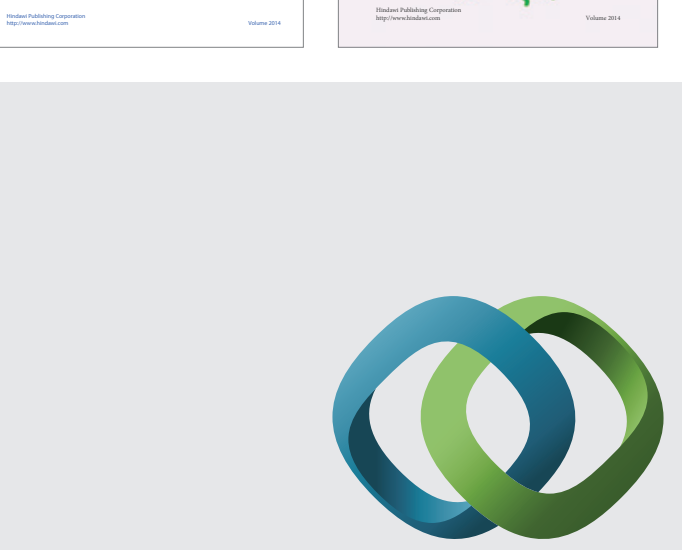

\section{Hindawi}

Submit your manuscripts at

http://www.hindawi.com
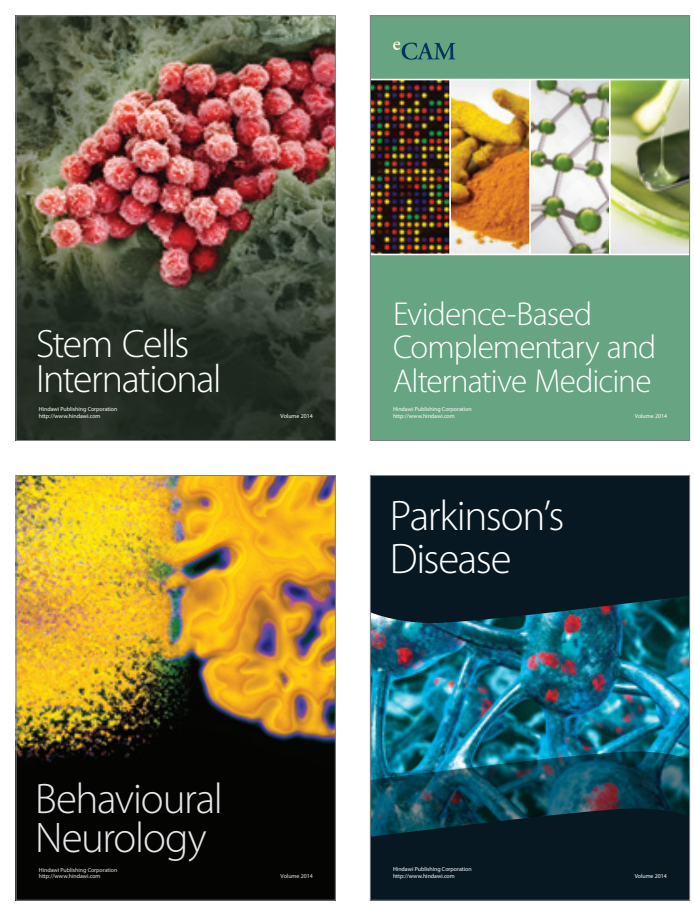

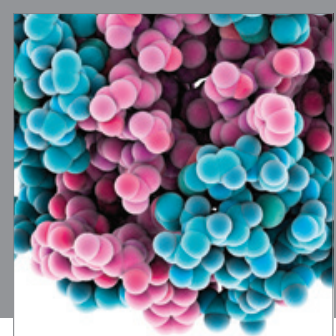

Journal of
Diabetes Research

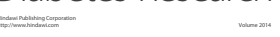

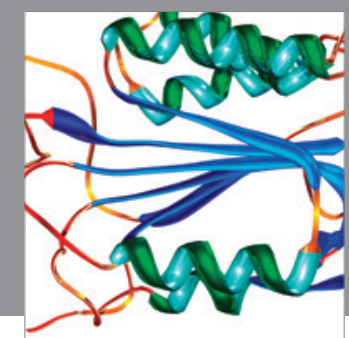

Disease Markers
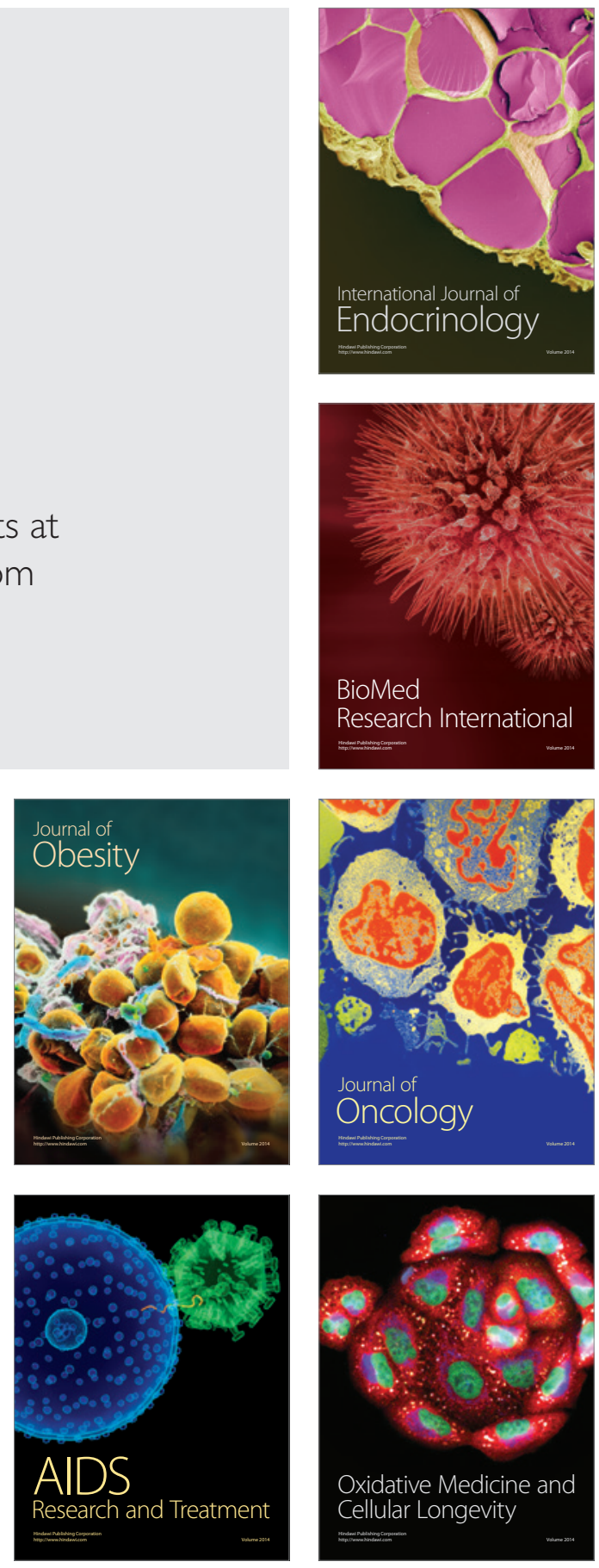